\title{
En Medellín la semilla del Vaticano II dio el ciento por uno
}

\author{
Teófilo Cabestrero, \\ Centro de Reflexión Teológica, \\ San Salvador.
}

Después de treinta años, ya se puede decir con verdad que en Medellín comenzó a expresarse, como magisterio pastoral del episcopado católico latinoamericano, una nueva conciencia de la Iglesia. En los procesos históricos de estos pueblos indo-afro-latinoamericanos ha recuperado la doble audacia evangélica de anunciar la buena nueva de Jesucristo a los pobres y oprimidos ( $c f r$. Lc 4, 14-22) y de dejarse evangelizar por ellos. Desde Medellín toma "cuerpo eclesial", en los pueblos crucificados de este continente la práctica profética y pastoral del primado de los pobres en el reino de Dios y en la Iglesia; práctica "acreditada" acá durante las tres últimas décadas con la persecución y el martirio.

Tal como vienen marchando la historia humana y las iglesias cristianas, todo esto se verá más claro y obtendrá mayor consenso a lo largo del siglo XXI. Por ello, este XXX aniversario de Medellín es buena hora para reivindicar su fidelidad a la misión profética de la Iglesia en los pueblos de América Latina, haciendo memoria de su eclesialidad y afirmando la vigencia de su espíritu en esta hora en que crece en forma indetenible y escandalosa la globalización concentrada de la riqueza, a costa del aumento de los excluidos de la vida sin posible defensa.

Esta reivindicación de Medellín es un deber de conciencia eclesial e históricá, y sería omisión grave callarla en vísperas del nuevo milenio. Muchos muertos, matados por defender la justicia, la dignidad y la vida de estos pueblos, claman contra el olvido y la impunidadı. Los martirologios del pueblo de Dios,

1. Ese "clamor" que se oyc cotidianamente en América Latina saltó al mundo en la clamorosa detención en Londres del general Pinochet, acusado de genocidio, secuestros y torturas, en paíscs curopcos. 
pedidos por Juan Pablo II a los episcopados, están listos para las celebraciones milenarias 2 . Y aún nos siguen matando al pueblo y a quienes defienden su vida, como al obispo Juan Gerardi, en la ciudad de Guatemala, con cínica impunidad3.

\section{Memoria de Medellín por dentro}

En el otoño europeo de 1965, cuando el Concilio Vaticano II se acercaba a su clausura, don Manuel Larraín, obispo de Talca (Chile) y presidente del CELAM, confiaba en Roma a los amigos su entusiasmo y su preocupación con estas palabras: "Lo que hemos vivido es impresionante, pero si en América Latina no estamos muy atentos a nuestros propios signos de los tiempos, el concilio pasará al lado de nuestra Iglesia, y quién sabe lo que vendrá después"4.

Esa confesión de aquel presidente del CELAM, que fue "el padre de Medellín", a pesar de morir en accidente de automóvil dos años antes de reunirse la conferencia, señala con precisión los tres factores más determinantes de Medellín: el Concilio Vaticano II, la realidad histórica latinoamericana, con "sus propios signos de los tiempos", y el CELAM de entonces.

La "memoria" de Medellín, que ahora ofrecemos, se limita a recordar la siembra que hizo en el episcopado de América Latina el Vaticano II, cuya semilla fructificó en la Conferencia General de Medellín, gracias a la escucha del Espíritu del reino de Dios, en los signos de los tiempos de la realidad histórica de aquel entonces, en este continente. La doble fidelidad de Medellín al reino de Dios y a la historia humana de sus pueblos acreditan su creciente vigencia eclesial en esta hora en que la globalización de los "excluidos" hace crecer la vigencia del misterio de "Cristo en los pobres".

\subsection{Semillas del Vaticano II para Medellín}

Las semillas del Vaticano II para Medellín no brotaron sólo de los documentos finales del Concilio, sino de todo lo que los 600 obispos de América Latina vieron, oyeron y compartieron con tantos obispos de otras latitudes -y con observadores, teólogos y asesores-, en tantas sesiones conciliares, pasillos, consultas, encuentros, foros, estudios, oración, lecturas, celebraciones y en las homilías

2. Así lo han manifestado los episcopados de Guatemala, El Salvador y otros países de Amćrica Latina.

3. Juan Gerardi, obispo auxiliar de la arquidiócesis de Guatemala, fue asesinado el 26 de abril de 1998, dos dias despućs de presentar públicamente, en la catcdral, la edición del Informe REMHI sobre las víctimas y horrores del conflicto armado, Guatemala, nunca más, $\mathrm{cn}$ cl cual cl cjército aparcce como responsable de la mayoría de las violaciones a los derechos humanos. Su asesinato no se ha esclarecido.

4. G. Gutićrrcz, "La rccepción del Vaticano II cn Latinoamćrica", en G. Albcrigo y J. P. Jossua, La recepción del Vaticano II, Madrid, 1987, p. 227, nota 27. 
y discursos de Juan XXIII y de Pablo VI. Toda la experiencia eclesial vivida en el proceso de las cuatro etapas del Concilio Vaticano II fue una siembra de cuatro años al viento del Espíritu, en aquel "pentecostés de la Iglesia", intensamente vivido entre 1961 y 1965.

\section{a) La semilla del nuevo espíritu eclesial}

Fue buena semilla para Medellín el "nuevo espíritu eclesial" que Juan XXIII inspiró desde la apertura del Concilio. Espíritu de "la esposa de Cristo", que hoy "prefiere usar más la medicina de la misericordia que la de la severidad", o espíritu de "una Iglesia madre amable, benigna, paciente y llena de misericordia", que, "lo mismo que un día Pedro al pobre que le pedía limosna, dice ella al género humano oprimido por tantas calamidades: No tengo oro ni plata, pero te doy lo que tengo: en nombre de Jesús de Nazaret, levántate y anda"5.

Ese espíritu del "amor pastoral" lo recalcó Pablo VI desde su discurso de apertura de la segunda etapa conciliar, cuando, tras la muerte de Juan XXIII, el nuevo Papa asumió la profética herencia conciliar de su predecesor; y lo intensificó en la apertura de la cuarta etapa, cuando habló del Concilio como "acto de amor" y dijo: "nos sentimos responsables ante toda la humanidad"6.

Tanto prendió en la eclesiología del Vaticano II ese espíritu de "la caridad pastoral", que el mismo Pablo VI afirmó en su alocución de clausura, el 7 de diciembre de 1965: "Aquella antigua historia del samaritano, ha sido la pauta de la espiritualidad de este Concilio" y "la religión de nuestro Concilio ha sido la caridad", hemos aprendido a amar más y a servir mejor a la humanidad"; "somos promotores del hombre", porque "cuando nos inclinamos ante el hombre, nos elevamos al reino de Dios"7.

\section{b) El diseño eclesiológico del Vaticano II}

Excelente semilla para Medellín fue el diseño eclesiológico del Vaticano II, cuyos dos trazos fuertes y nucleares se grabaron pronto en bastantes obispos latinoamericanos: volver a Jesucristo, "abrazar su estilo" (como les pedía Pablo VI) e ir con su espíritu al mundo humano, "no a dominarlo, sino a escucharlo, acogerlo y servirlo" 8 . ¿Y a dónde conducía el ir así "al mundo humano" de

5. Juan XXIII en la apertura del Concilio Ecuménico Vaticano II. Texto íntegro en Concilio Vaticano II, BAC 252, Madrid, 1966, pp 749-756, citas en pp. 753-754.

6. Pablo VI al abrir la segunda sesión del Vaticano II, el 29 de septiembre de 1963 , op. cit., pp. 761-775, y al abrir la cuarta sesión, el 10 de septiembre de 1965, op. cit., pp. 803-807.

7. Pablo VI, alocución pronunciada en la clausura final del Concilio, op. cit., pp.824 831, citas en pp. 827-830.

8. Pablo VI en la apcrtura de la segunda sesión, op. cit., p. 773. 
América Latina? Conducía a toparse con los pobres, a encontrarse con las mayorías empobrecidas, que, además de empobrecidas, eran también creyentes.

El 7 de diciembre de 1965, cuando se clausuraba el Concilio, ya se estaba fraguando entre la directiva del CELAM y Pablo VI la aplicación del Vaticano II a la Iglesia en América Latina. Y varios pensamientos expresados por el Papa en su homilía final quedaron sembrados para hacerse fecundos en Medellín. Entre otros, sin duda, estas dos afirmaciones:

Quizás nunca la Iglesia como durante este Concilio se había sentido impulsada a conocer a la humanidad que le rodea, a acercarse a ella, a comprenderla, a penetrarla, servirla y evangelizarla en sus mismas rápidas transformaciones 9 .

En el rostro de cada ser humano, sobre todo si se ha hecho transparente por sus lágrimas y por sus dolores, podemos y debemos reconocer el rostro de Cristo (Mt 25, 40), y en el rostro de Cristo podemos y debemos reconocer el rostro de Dios Padre11.

¿Cómo no oír los ecos de esas palabras en Medellín, desde los textos sobre Justicia, sobre la Paz, sobre los Pobres y la Pobreza en la Iglesia, hasta el Mensaje final a los pueblos de América Latina? Y esos ecos resonarían en Puebla y en Santo Domingo'l, multiplicando el ciento por uno que dio en Medellín la semilla del Vaticano II y confirmando así, décadas después, que Medellín fue el momento fundante de la recepción latinoamericana del Vaticano Il.

\subsection{La semilla de la "Iglesia de los pobres"}

Según confesión de algunos obispos latinoamericanos, de toda su vivencia en la Roma conciliar, lo que caló más hondo en ellos fue la semilla de "la Iglesia de los pobres". Si es cierto que tal semilla quedó escasa en los documentos conciliares ( $L G$ 8; GS 1 y $A G 5$, son los tres lugares significativos donde quedó esa semilla), no es menos cierto que se sembró abundosa, dentro y fuera del aula conciliar, desde las vísperas del Concilio hasta su clausura final.

9. El subrayado es nuestro para aludir al signo de los ticmpos de Amćrica Latina que motivó el objetivo general y el título de los documentos de Medellín: La Iglesia en la actual transformación de América Latina a la luz del Concilio.

10. Pablo VI, alocución en la clausura del Vaticano II, op. cit., pp. 827-830.

11. Diez años después de Medellín, Pucbla hablaba de ver el rostro sufricnte de Cristo en los rostros doloridos y tristes de niños, jóvenes, indígenas, afroamericanos, campesinos, obrcros, subcmpleados y descmpleados, marginados y ancianos de Amćrica Latina (nn. 31-39). Y Santo Domingo alargó esa lista y pidió contemplar el rostro sufriente de Cristo en nuevos rostros de pobres, veinticuatro años despućs de Medellín (nn. 178-179). 
Y hoy merece especial atención la densidad de aquella siembra permanente en el Concilio para una "Iglesia de los pobres", que no fructificó al cien por ciento en el Concilio mismo (inevitablemente eurocéntrico y dominado por otras urgencias), pero que en América Latina daría el ciento por uno, al ser fecundada esa semilla por estos pueblos, cuando su realidad y su conciencia histórica ardían en necesidad y ansias de urgentes cambios profundos.

\section{a) La siembra de Juan XXIII sobre "la Iglesia de los pobres"}

El primer sembrador de esa semilla fue Juan XXIII. Treinta días antes de inaugurar el Concilio, el 11 de septiembre de 1962, el Papa abrió su radiomensaje al mundo hablando de "la gran expectación ante el Concilio ecuménico a un mes de su comienzo oficial". Y, en el contexto de que "la Iglesia siente el deber de hacer honor a sus responsabilidades frente a las exigencias y necesidades actuales de los pueblos", lanzó este mensaje: "Otro punto luminoso. Frente a los países subdesarrollados, la Iglesia se presenta como es y quiere ser: como la Iglesia de todos y, particularmente, la Iglesia de los pobres"12.

Ese punto luminoso de Juan XXIII, que suscitó comentarios y resonó varias veces en el aula conciliar, inspiró también un foro sobre "la Iglesia de los pobres", en cuyas sesiones romanas, a lo largo de las cuatro etapas del Concilio, participaron obispos, cardenales, peritos y teólogos con asidua presencia de América Latina. Ahí se gestó, como recordaremos enseguida, uno de los signos eclesiales más históricos del Vaticano II: la pública opción por los pobres de un grupo de obispos miembros del Concilio.

\section{b) La siembra de Pablo VI sobre "la Iglesia de los pobres"}

También Pablo VI sembró esa semilla, cuando empuñó el timón del Vaticano II, después de morir Juan XXIII. En su primer discurso, al abrir la segunda sesión conciliar, el 29 de septiembre de 1963, afirmó el nuevo Papa: "La Iglesia, abierta sobre el mundo, mira con particular interés a determinadas categorías de personas. Mira a los pobres, a los necesitados, a los afligidos, a los hambrientos, a los enfermos, a los encarcelados; mira a toda la humanidad que sufre y llora; ésta le pertenece por derecho evangélico y Nos nos complacemos en repetir a cuantos la forman: Venid a mí todos los que sufrís... (Mt 11, 28)"13.

Más incisiva aún fue para los obispos latinoamericanos otra siembra posterior de Pablo VI durante el Concilio. Cuando el papa regresó a Roma, después

12. Un extenso comentario de Gustavo Gutiérrez a ese punto de luz de Juan XXIII, en Alberigo-Jossua, op. cit., pp. 221-225.

13. Pablo VI en la apcrtura de la segunda scsión del Concilio Vaticano II, op. cit., p. 773. 
de su histórico discurso ante la ONU sobre la paz, el 5 de octubre de 1965 (a dos meses del final del Concilio), exhortó a la asamblea conciliar en estos términos:

La paz debe tener por fundamento la justicia, hagámonos, pues, abogados de la justicia, porque el mundo tiene una gran necesidad de justicia y Cristo quiere que estemos sedientos de justicia. Y sabemos que la justicia es progresiva, y cuanto más progrese la sociedad más se despierta en ella la conciencia de lo imperfecta que es su estructuración porque salen más a la luz las desigualdades estridentes e implorantes que afligen a la humanidad. ¿No son esas desigualdades entre los ciudadanos y entre las naciones la mayor amenaza para la paz? Es preciso que nos preocupemos de la situación de los pueblos en vías de desarrollo. Digámoslo más claro: nuestro amor para con los pobres del mundo, cuyo número es incontable, tiene que ser más solícito, más eficaz, más generoso [...] Al testimonio de la palabra — concluía el Papa- permítanos el Señor añadir ahora el testimonio de la acción.

Esa semilla (regada luego por la encíclica Populorum Progressio) fecundó los documentos de Medellín sobre Justicia, Paz y La pobreza en la Iglesia.

La determinación con que Pablo VI exhortó en esa ocasión a los miembros del Concilio, en términos tan cercanos a los de Juan XXIII, en aquel radiomensaje al mundo ("en los pueblos subdesarrollados la Iglesia quiere ser, particularmente, la Iglesia de los pobres"), nos hace pensar en cuánto tuvo que impresionarle al entonces cardenal Montini, lo que el arzobispo de Bolonia, Giacomo Lercaro, dijo en el aula conciliar al final de la primera sesión.

\section{c) La impactante siembra de Lercaro sobre "la Iglesia de los pobres"}

La experiencia del "impacto" proviene de los testigos directos, de quienes oyeron de viva voz al cardenal Lercaro. Los periodistas lo divulgaron. El eminente cronista del Vaticano II, que fue José Luis Martín Descalzo (digno también por eso de emocionado recuerdo), nos lo transmitió al abrir así su resumen de las palabras de Lercaro: "El gran momento de la sesión de hoy se ha vivido durante la intervención del cardenal Lercaro. 'Se podía cortar el silencio con un cuchillo', me comentaba uno de los asistentes"'14.

Calibremos (casi cuarenta años después) la fibra de la semilla que sembró, en plena asamblea conciliar, el cardenal arzobispo de Bolonia, Giacomo Lercaro, cuando el Concilio aún buscaba su rumbo, al término de aquella agitadísima primera sesión. La propuesta de aquel arzobispo italiano, cuya fuerza y acierto podemos valorar hoy más que entonces, merece el espacio que nunca se le dio para divulgarla. Y es pertinente darle ese espacio sin regateos,

14. J. L. Martín Descalzo, Un periodista en el Concilio I, Madrid, 1964, pp. 326-327. 
en esta evocación de Medellín, ya que en él fructificó como en ningún otro tiempo y lugar eclesial, aquel vigoroso e inspirado reclamo al Concilio Vaticano II acerca de "la Iglesia de los pobres". Reproduzcamos por extenso las palabras que escucharon los miembros del Concilio al cardenal Giacomo Lercaro, el día 6 de diciembre de 1962:

[...] Si alguna conclusión podemos sacar al final de esta sesión de nuestro Concilio es ésta: dos meses de fatigas y de búsqueda verdaderamente generosa, humilde, libre y fraterna, con la asistencia del Espíritu Santo, nos han llevado a comprender mejor lo que el Vaticano II debe proponer a los hombres de nuestro tiempo para iluminar sus corazones con una luz de verdad y de gracia. Lo que debemos proponerles es, sin duda, el íntimo misterio de la Iglesia como el "gran sacramento" de Cristo, del Verbo de Dios que se revela, que habita, que vive y actúa entre los hombres [...].

Sin embargo, todos sentimos que al Concilio le ha faltado hasta ahora algo: tantos elementos preciosos, quedan fragmentados sin haber encontrado todavía un principio vivificador y unificante.

¿Dónde encontraremos ese impulso vital, esa alma, digamos esa plenitud del Espíritu? Sólo en un acto de sobrenatural docilidad de cada uno de nosotros y de todo el Concilio al indicador que parece hacerse siempre más claro e imperativo. Esta es la hora de los pobres, de los millones de pobres que están por toda la tierra. Esta es la hora del misterio de la Iglesia madre de los pobres, esta es la hora del misterio de Cristo sobre todo en el pobre.

I. Ante todo, también yo insisto sobre cuanto ha pedido el cardenal Suenens y sobre las precisiones hechas ayer por el cardenal Montini acerca del fin de este Concilio, la agenda de los trabajos futuros, el orden y la concentración de asuntos y, sobre todo, de la necesidad de una doctrina De Ecclesia [...].

II. Pero la finalidad más específica de esta intervención mía es reclamar la atención, más todavía de cuanto se ha hecho, sobre un aspecto de este misterio de Cristo en la Iglesia, que me parece no sólo perennemente esencial, sino también de suprema actualidad histórica. Quiero decir: el misterio de Cristo en la Iglesia ha sido siempre, pero hoy lo es más particularmente, el misterio de Cristo en los pobres. En cuanto que la Iglesia, como ha dicho el santo padre Juan XXIII, si es la Iglesia de todos, hoy es especialmente "la Iglesia de los pobres".

Leyendo el índice analítico de los esquemas que ayer nos distribuyeron, me ha impactado esta carencia: en los asuntos que han sido propuestos, o que serán propuestos a nuestra consideración y discusión, no se ha tenido en cuenta -en el modo consciente y explícito y en la medida histórica proporcionada que hubiera sido necesario- este aspecto esencial y primario del misterio de Cristo; aspecto preanunciado por los profetas como signo incon- 
fundible de la consagración y misión mesiánica de Cristo (Is 61, 1-2 y Lc 4, 18); aspecto magnificado por la misma madre del Salvador en la encarnación del Verbo (LC 1, 52-53); aspecto promulgado por el nacimiento, por la infancia, por la vida oculta y por la enseñanza pública de Jesús (Lc capítulos 1-4); aspecto que constituye la ley fundamental del reino de Dios; aspecto que condiciona todo el flujo de la gracia y la vida de la Iglesia, desde la comunidad apostólica hasta las horas de la mejor renovación interior y expansión exterior de la misma Iglesia (Hch 2, 44-45; 4, 32-35; 2Cor 8, 9-14); aspecto, en fin, que será sancionado por la eternidad con el premio o el castigo en el glorioso advenimiento del Hijo de Dios al final de los tiempos (Mt 25, 31ss).

III. Por eso al concluir la primera fase de nuestro Concilio, me parece que tenemos el deber de reconocer y proclamar solemnemente que no cumpliremos nuestro deber, ni sabremos entender la voluntad de Dios y la esperanza de los hombres sobre este Concilio, si no ponemos como centro de su enseñanza doctrinal y de su obra de salvación en la Iglesia, el misterio de Cristc en los pobres y el anuncio del evangelio a los pobres.

Este es el deber más claro, más concreto, más actual y más imperativo de un tiempo en el que, más que en ningún otro, los pobres no parecen ser evangelizados y sus corazones parecen alejados y extraños al misterio de Cristo en la Iglesia; época en la que, por otro lado, la conciencia humana pregunta e investiga con ansiosas y dramásticas preguntas el por qué de la pobreza y el destino de los pobres como personas y como pueblos que cobran conciencia nueva de sus derechos; época en que la pobreza de muchísimos (dos tercios de la humanidad) es una ofensa de la desmedida riqueza de unos pocos, y en la que más que nunca la pobreza es temida y despreciada por el instinto de las multitudes.

IV. Pero, al señalar - como otros han hecho- el problema de la evangelización de los pobres, no pretendo que se añada otro tema a la lista tan larga de los temas que el Concilio ha de estudiar. Yo me siento en el deber de decir que no responderemos a las más profundas y verdaderas exigencias de nuestro tiempo, incluida nuestra gran esperanza de promover la unidad de todos los cristianos, sino que las eludiremos, si dejamos que el Concilio trate el problema de la evangelización de los pobres de nuestro tiempo como un tema añadido a los otros temas. No se trata de un tema, sino, en cierto sentido, del único tema del Vaticano II.

$\mathrm{Si}$, como he dicho varias veces -incluso ayer - en esta aula, el tema de este Concilio es la Iglesia, se puede y se debe precisar que la formulación más conforme a la verdad eterna del Evangelio y la más adecuada a la situación histórica de nuestro tiempo es ésta: el tema del Concilio es la Iglesia en cuanto es particularmente Iglesia de los pobres, de todos los millones y millones de pobres individualmente, y colectivamente de los pueblos pobres de toda la tierra. 
V. Precisado en esos términos el objeto propio e inmediato de este Concilio, permítaseme hacer algunas propuestas concretas en vista al trabajo de la próxima sesión:

1) Que en el trabajo que desarrolle el Concilio de ahora en adelante, encuentre, no sólo un lugar, sino el primer lugar, la formulación de la doctrina evangélica de la santa pobreza de Cristo en la Iglesia: el misterio de la elección divina que ha escogido la pobreza como un signo y un modo - sacramentum magnum, dico, in Christo et in ecclesia, (Ef 5, 32)- un signo y un modo preferencial de presencia y de fuerza operativa y salvífica del Verbo encarnado entre los hombres...

2) Que en nuestros trabajos demos prioridad a la formulación de la doctrina evangélica de la eminente dignidad de los pobres como miembros de la Iglesia, porque son los miembros en los que preferencialmente el Verbo de Dios encarnado oculta el fulgor de su gloria hasta el fin de los tiempos.

3) Que en todo nuestro trabajo y en la nueva impostación de los esquemas -como muchos reclaman- se ponga ẹ claro y se tenga siempre presente la conexión ontológica estrechísima que existe entre la presencia de Cristo en los pobres, la presencia de Cristo en la eucaristía que funda y constituye la Iglesia, y la presencia de Cristo en la jerarquía que enseña y pastorea la Iglesia. Se trata de tres aspectos del único misterio [...].

4) Que en cada problema práctico de la renovación de las instituciones eclesiásticas y de las formas de evangelización, se tenga siempre presente y nos esforcemos por clarificar la conexión histórica que existe entre el reconocimiento sincero y coherente de la eminente dignidad del pobre en el reino de Dios y en la Iglesia, y, por otra parte, el realismo de las posibilidades y los límites de la evangelización en nuestro tiempo, así como de los modos y formas nuevas necesarias en el anuncio a los hombres de nuestra época $[\ldots]$.

7) Si somos dóciles a las llamadas que nos hace la Providencia para afirmar y buscar el primado de la evangelización de los pobres, no será difícil, con la ayuda del Espíritu del Señor y de María, que podamos encontrar para todos los problemas doctrinales y prácticos un modo "auténtico" de presentar integralmente y sin ningún recorte el Evangelio eterno e inmutable de Dios; y de tal modo presentarlo que sea lazo de unión de la familia humana así como el Padre y Cristo son uno solo; y que toque los corazones y llene de esperanza a los hombres de nuestro tiempo, especialmente a los pobres en la iglesia de Cristo, el cual siendo rico se hizo pobre para enriquecernos con su gracia y con su gloria15.

15. G. Lercaro, intervención en la CG 35, 6 de diciembre de 1962. Acta Synodalia Sacrosancti Concilii Ecumenicii Vaticani II, Vol I, Periodus Prima, Pars IV, 327330. 
José Luis Martín Descalzo sólo añadió a su breve resumen de la intervención del cardenal Lercaro este mínimo apunte: "Se comprende que el aire se cortase con un cuchillo, y, que, al concluir, la asamblea estallase en uno de los más vivos aplausos que ha conocido el Concilio"16.

\section{Fruto y semilla: la opción de unos obispos}

Martín Descalzo dedicó su crónica del Concilio del 30 de noviembre de 1965 a la opción por la pobreza evangélica y por los pobres que un grupo anónimo de obispos hizo pública, en un documento de tres páginas. La iniciativa brotó — nos decía el cronista - "del grupo de obispos que durante estos cuatro años se han reunido (en el Colegio Belga de Roma) para estudiar el tema 'La Iglesia de los pobres'. El documento reúne firmas episcopales y sé que ayer sobrepasaba el centenar. Es un documento significativo y quiero recogerlo en estas crónicas porque estoy seguro de que permanecerá como uno de los 'símbolos' de este Concilio Vaticano II y de su espíritu". Después daba el texto íntegro del documento, y preguntaba al final el periodista: “ ¿Es necesario añadir una sola palabra a un documento de este calibre?"17.

El documento impactó por el realismo evangélico de los compromisos que asumía un grupo anónimo de obispos, en su mayoría de iglesias del tercer mundo, entre ellos, el brasileño Helder Cámara. Fue un grupo episcopal simbólico de las iglesias donde el Concilio suscitó, con mayor rapidez y decisión, "la Iglesia de los pobres", señalada por Juan XXIII, en aquel punto luminoso que vio en vísperas del Concilio...

Estos obispos abrían su declaración confesando sentirse en el Concilio Vaticano II "iluminados sobre las deficiencias de nuestra vida de pobreza según el Evangelio; animados mutuamente a emprender un camino en el que cada uno de nosotros pueda evitar la singularidad y la presunción; unidos a todos nuestros hermanos en el episcopado; confiados sobre todo en la fuerza y la gracia de Nuestro Señor Jesucristo y en la oración de los fieles y de los sacerdotes de nuestras diócesis; situados con el pensamiento y la oración ante la Trinidad, ante la Iglesia de Cristo, ante los sacerdotes y fieles de nuestras diócesis, en la humildad y la conciencia de nuestra debilidad, pero con la determinación y fuerza con que Dios quiera agraciarnos, nos comprometemos a lo siguiente".

Asumían trece compromisos concretos de estilo de vida en pobreza real y evangélica; renunciaban a nombres y títulos de grandeza y poder ("Eminencia, Excelencia, Monseñor") y a privilegios y favores pasivos o activos; renunciaban a riquezas en vivienda y posesión de bienes muebles o inmuebles y a cuentas

16. J. L. Martín Descalzo, op. cit., p. 327.

17. Op. cit., IV, Madrid, 1966, pp. 490-493. 
corrientes personales; y se comprometían a practicar y promover la justicia, la solidaridad y el servicio. "Cuando lleguemos a nuestras respectivas diócesis concluían- daremos a conocer a nuestros diocesanos nuestra resolución, rogándoles que nos ayuden con su comprensión, su colaboración y sus oraciones. Que Dios nos ayude a ser fieles".

Unos lo llamaron "Pacto de las catacumbas", porque en ellas fue suscrito el documento al amparo de la sangre de los mártires de Roma. Otros lo apellidaron "Esquema IV", sugiriendo que merecía ser el último documento del Concilio Vaticano II.

El grupo anónimo de obispos que declaró así su opción evangélica por la pobreza eclesial y por los pobres, se mantuvo unido y testimoniante. Entre sus mensajes, destacó, a los dos años del Concilio, su encendido apoyo a la carta encíclica de Pablo VI Populorum Progressio.

\section{Pablo VI y el CELAM, de Roma a Medellín}

Con motivo del décimo aniversario de la creación del CELAM, el 24 de noviembre de 1965 (dos semanas antes de clausurarse el Concilio) Pablo VI reunió a los obispos de la directiva y equipos del CELAM, y a todo el episcopado de América Latina que participaba en el Concilio.

En su saludo, Pablo VI dijo al presidente del CELAM, don Manuel Larraín: "le expresamos nuestra calurosa felicitación a los pocos días de su reelección a la presidencia del Consejo Episcopal Latinoamericano"18. Y, en su exhortación, dijo entre otras cosas a los obispos de la Iglesia católica en América Latina: "América Latina presenta una sociedad en movimiento, sujeta a cambios rápidos y profundos [...] Defender lo que existe ya no basta, porque ya no es adecuado a toda la población y a todas las necesidades, y porque aun lo que existe se ve arrastrado por el movimiento de transformaciones". Y habló de los contrastes, entre riqueza y pobreza y de los amplios sectores que permanecen inmóviles y "maniatados por el analfabetismo todavía difundido". Y subrayó: "la masa de la población cobra una conciencia cada vez mayor de sus difíciles condiciones de vida y cultiva un deseo irrefrenable y bien justificado de cambios satisfactorios, manifestando, a veces de modo violento, un creciente inconformismo"... "Toda solución que no tenga en cuenta esa compleja realidad, corre el peligro de resultar inadecuada e ineficaz". Sin embargo, "no faltan, lamentablemente, quienes permanecen cerrados al soplo renovador de los tiempos y que se muestran faltos de sensibilidad humana y de una visión crítica de los problemas que se agitan a su alrededor"...

18. Pablo VI, Exhortación Apostólica al Episcopado de Amćrica Latina cn Roma, en op. cit., pp. 851-862. 
Ante ese diagnóstico y esas previsiones de Pablo VI sobre América Latina, más de un obispo recordó los temores que expresaba don Manuel Larraín cuando decía: "si en América Latina no estamos muy atentos a nuestros propios signos de los tiempos, el Concilio pasará de largo de nuestra Iglesia y quién sabe lo que vendrá después".

Al mismo tiempo, y por todo eso, "la fe del pueblo latinoamericano - les dijo Pablo VI- debe alcanzar todavía una plena madurez de desarrollo". Y les habló de condiciones y caminos para el trabajo pastoral de la Iglesia en América Latina, de criterios de acción (unidad, planificación y prioridades para "concentrar el esfuerzo de evangelización"). Y del papel del clero, de los laicos, de los religiosos y religiosas. De la doctrina social de la Iglesia y de las necesarias vocaciones. De los jóvenes, de los medios de comunicación y de la necesidad de orientar la evangelización a "transformar las parroquias en verdaderas y auténticas comunidades eclesiales en las que nadie se sienta extraño y de las que todos sean parte integrante". Y les habló también de la "acción social".

"La conciencia de ser hombres de nuestro tiempo nos hará conocer también la necesidad imperiosa y la medida justa de nuestra participación humilde pero sincera en la solución de los problemas humanos y de la hora actual". Les recordó lo que dijo días antes a toda la asamblea conciliar sobre la necesidad de hacerse "abogados de la justicia" y de "tener hambre y sed de justicia". Y añadió:

De la justicia, el aspecto social es el que más afecta e interesa al mundo actual en general y al latinoamericano en especial, porque en América Latina los contrastes son intensos y profundos. La súplica dolorosa de tantos que viven en condiciones indignas de seres humanos, no puede dejar de afectarnos, venerables hermanos, y no puede dejarnos inactivos; no puede y no debe quedar desoída e insatisfecha. Debemos asumir un compromiso solemne a fin de que la Iglesia, movida e inspirada siempre por la caridad de Cristo que cierra la vía a soluciones de desorden y de violencia, tome sus responsabilidades para la consecución de un sano orden de justicia social para todos. El trabajo que ha de efectuarse es delicado y arduo; la necesidad de satisfacer también en esto un imprescindible deber pastoral nos dará el necesario valor evangélico.

Ya estaban los obispos latinoamericanos ante el horizonte de Medellín. En menos de tres años, verían a Pablo VI en Colombia. Allí habló también al pueblo latinoamericano en los campesinos y en los moradores de un barrio suburbano. Con el CELAM y el episcopado de América Latina inauguró oficialmente la Segunda Conferencia General del Episcopado, en la catedral de Bogotá, el 24 de agosto de 1968. Pablo VI calificó de "un hecho histórico, la primera visita personal del Papa a sus hermanos e hijos de América Latina", añadiendo que "por una convergencia de circunstancias proféticas, esta visita "inaugura 
una nueva etapa de la vida de la Iglesia en América Latina". Pablo VI calificó la obra de evangelización en América Latina de inacabada y señaló su inmediato porvenir.

La obra, como todos sabemos, no está acabada. Más aún, el trabajo realizado denuncia sus límites, pone en evidencia nuevas necesidades, exige algo nuevo y grande. El porvenir reclama un esfuerzo, una audacia, un sacrificio que pone en la Iglesia un ansia profunda. Estamos en un momento de reflexión total. Nos invade, como una ola desbordante, la inquietud característica de nuestro tiempo especialmente en estos países proyectados hacia su desarrollo completo y agitados por la conciencia de sus desequilibrios económicos, sociales, políticos y morales. También los pastores de la Iglesia hacen suya el ansia de los pueblos en esta fase de la historia de la civilización 19.

Frente "a la inestabilidad" y al "temor" que enfatizó como amenazas envolventes, comenzó por dirigir a la asamblea el "¡no temáis!" de Jesús a sus discípulos: "Esta es para la Iglesia una hora de ánimo y de confianza en el Señor". Y desarrolló tres líneas de orientación, espiritual, pastoral y social, en un discurso que no eludía las urgentes y comprometedoras necesidades de cambios profundos, ni ahorraba las adventencias frente a las tentaciones del odio y la violencia para cambiar las injustas situaciones de "desigualdades opresoras". Muestra esas dos vertiendes de su discurso este párrafo resumen:

Si nosotros debemos favorecer todo esfuerzo honesto para promover la renovación y la elevación de los pobres y de cuantos viven en condiciones de inferioridad humana y social, si nosotros no podemos ser cómplices con sistemas y estructuras que encubren y favorecen graves y opresoras desigualdades entre las clases y los ciudadanos de un mismo país, y si nosotros debemos poner en acto un plan efectivo para remediar las condiciones insoportables de inferioridad que frecuentemente sufre la población menos pudiente, nosotros mismos repetimos una vez más a este propósito: ni el odio, ni la violencia, son la fuerza de nuestra caridad [...] La transformación profunda y previsora de la cual tiene necesidad la sociedad en muchas situaciones actuales, nosotros la promoveremos amando más intensamente y enseñando a amar con energía, con sabiduría, con perseverancia, con acciones prácticas, con confianza en los hombres, con seguridad en la ayuda paterna de Dios y en la fuerza innata del bien.

En nombre del CELAM y de los obispos y demás miembros convocados a la Segunda Conferencia General que Pablo VI inaguraba, el cardenal Landázuri, arzobispo de Lima y copresidente de esa conferencia, había saludado a Pablo VI

19. Pablo VI, Discurso de apertura de la Segunda Conferencia Gencral del Episcopado Latinoamericano, en La Iglesia en la actual tranformación de América Latina a la luz del Concilio, I Ponencias, Mćxico, 1976, pp. 25-38. 
diciéndole: "Permitid que manifieste nuestra gran alegría al recibir al peregrino del desarrollo de los pueblos que sufren. ¡Bienvenido a nosotros, peregrino de la paz!". El breve discurso de bienvenida del cardenal primado del Perú, en el que brilló el magisterio reciente de Pablo VI, preanunciaba en forma transparente el ciento por uno del Vaticano II en Medellín, fecundado por los signos de los tiempos de la realidad histórica latinoamericana:

Una situación anormal está instalada en América Latina, ahí donde se ignora la dignidad de la persona humana y donde grandes masas aguardan todavía el signo de su redención. La alternativa para los hombres responsables de nuestro momento histórico no está entre el mantenimiento de la actual situación y el cambio; tal planteamiento está superado. Todos estamos concordes en la necesidad de transformaciones profundas y rápidas. La alternativa es sobre el modo de llevar a cabo tan urgente tarea [...].

En América Latina la salvación, que es realización del reino de Dios, abarca la liberación de todo el hombre, el paso para cada uno y para todos, de condiciones de vida menos humanas a condiciones más humanas. Esto es lo que anhelamos y lo que nos empeñaremos en realizar. Para ello debemos compenetrarnos vivamente del mensaje de Cristo para comprender que el reino de Dios no habrá alcanzado su madurez allí donde no haya desarrollo integral. Por tanto, en nuestro servicio pastoral buscaremos las formas de encarnar hoy en la Iglesia el amor del Señor [...] En un esfuerzo decidido de constante conversión, de vivir en el amor evangélico, no podemos menos de reconocer que es la Iglesia, nuestra Iglesia en América Latina, la que se pone en cuestión, profundizando la conciencia que tiene de sí misma [...] El pueblo de Dios que vive y sufre en estas tierras quiere decir de sí mismo, por fidelidad al Señor, que desea servir a la humanidad y por ello quiere escrutar en los signos de los tiempos lo que el Espíritu desea de la Iglesia. Solamente así el pueblo de Dios será en estas jornadas de la historia, signo alzado entre las naciones. A la luz del Vaticano II queremos ver si hemos puesto en práctica su idea central, hondamente cristiana, del servicio; y queremos comprender hasta dónde ha.de llevarnos este servicio al hombre.

Y porque nos preocupa la totalidad del hombre en el proceso de tranformación y desarrollo de nuestros pueblos, queremos que ellos mismos sean autores y realizadores de su progreso, ofreciéndoles por nuestra parte el compromiso que brota de la fraternidad eucarística o, para decirlo con la iluminada palabra de Vuestra Santidad: "La participación en el banquete eucarístico es una invitación a corregir las injustas desigualdades entre personas, sectores o pueblos. Acompañe, pues, a la comunicación de la riqueza sobrenatural por parte de Cristo, nuestro Salvador y hermano, la solidaridad, la distribución más justa de los bienes de la tierra entre los miembros de las comunidades humanas". 
Para ello es necesario un cambio urgente, profundo, que no sustituya una miseria con otra; un cambio que no implante el odio donde sólo debe reinar la fraternidad. Necesitamos un orden nuevo más humano y más cristiano $[\ldots]$.

Esta nuestra acción que sabemos difícil, llena de riesgos e incomprensiones, será el signo de que la transformación, el progreso y el desarrollo en América Latina no será ambiguo. Nuestro propósito en nombre del Señor lo hará plenamente humano por estar instaurado en Cristo Jesús20.

20. J. Landázuri, Saludo al Papa Pablo VI en la apertura de la Segunda Conferencia General op. cit., pp. 17-21. 